\title{
Aspects Regarding Thermal-Mechanical Fatigue of Shape Memory Alloys
}

\author{
Petrică Vizureanu, Dragoș-Cristian Achiței, \\ Mirabela-Georgiana Minciună and \\ Manuela-Cristina Perju \\ Additional information is available at the end of the chapter \\ http://dx.doi.org/10.5772/intechopen.77991
}

\begin{abstract}
This chapter presents advanced researches about the using of metallic alloys with shape memory properties in construction and exploitation of parts subjected to combined stress by thermal and mechanical fatigue during their functioning. The shape memory alloys (SMAs) have a series of properties much different from the usual metallic materials. Their main characteristic is recovery/returning from plastic deformation by heating, considering that in some cases at temperature changing, the shape modification is reversible. In the case of parts made from SMA, which work in conditions by thermal and mechanical stresses and temperature variations, the resistance evaluation at thermal and mechanical fatigue is absolutely necessary. Like researching domain, regarding thermal and mechanical fatigue behavior, it was selected the shape memory $\mathrm{Cu}$-based alloy. The achieved researches, concerning methodology, investigation equipment, experimental results, allow evaluating and estimating the shape memory properties. Losing the shape memory properties of SMA, in requested conditions, namely amnesia, so to the calculation of fatigue resistance must be taken into account by this fundamental property. The expression of the fatigue state, through losing the memorizing capacity, represents a designing indicator, which ensures the guaranty of properties in fatigue conditions, through applying of fatigue cycles. To determine the fatigue resistance of SMA was necessary specific requests. The properties are guaranteed for a certain number of fatigue cycles. The experimental data, presented in this chapter, offer to scientists some information about the SMAs, Cu-based. These data can be used in designing and manufacturing of new parts for different devices.
\end{abstract}

Keywords: shape memory alloys, properties, shape memory effect, thermal and mechanical fatigue, Cu-based alloy 


\section{Introduction}

The SMAs present some properties which are not found to metallic alloys used in practice. Characteristic to these alloys it is the capacity to change the geometric shape at temperature modification. After heating up to a imposed temperature, the part is cooled until ambiance temperature and returns to his initial shape. In some conditions, the shape changing can be reversible and the material can memorize two geometric shapes: the shape from high temperature (hot shape) and the shape from low temperature (cold shape). The shape changing is realized due to shape memory effect (SME). Through SME, the alloy can do mechanical work in the passing time from cold shape to hot shape.

SMAs can be classified, according to the alloying elements, in following classes: Nickel-based alloys, Copper-based alloys, Iron-based alloys, and Noble Metals-based alloys, Exotic alloys. Cooper-based alloys, like $\mathrm{Cu} \mathrm{Al}, \mathrm{CuAlNi}, \mathrm{AuCd}, \mathrm{NiAl}, \mathrm{CuZn}, \mathrm{CuZnAl}$ are named $\beta$ phase alloys. There are numerous types of SMAs, but most of them have high manufacturing costs due to noble or rare metals from composition or to complex obtaining technology. Interest presents NiTi, $\mathrm{CuZnAl}, \mathrm{CuAlNi}$ alloys which are used in various applications. The most important shape memory phenomena are: (1) pseudo-elastic or pseudo elasticity effect (PSE); (2) shape memory simple effect (SME); (3) double sense shape memory effect (DSSME); and (4) vibrations damping effect.

A less studied chapter is the behavior of these alloys at thermal fatigue and that is because SMA can work: with free return, with retained return, with manufacturing of mechanical work, and pseudo-elasticity. In each of these cases, the parts of SMAs will be heated and then cooled to obtain the proposed goal. Between the hot shape and the cold shape of SMA, there exists a difference of energy. The change reversibility of the two shapes stays at the base of many applications. In this case, the reproducibility of the two shapes has a high importance. After a certain number of functioning cycles, the reproducibility of the two shapes is affected, so does the shape memory property.

Nowadays, some SMAs have usages in domains like:

- aerospace and naval: flaps for aircrafts, solar panels benders for Hubble telescope or Clementine satellite;

- robotics: devices for channel drainage, actuators for tasks manipulation robots;

- medical: medical instruments, crack bones restoration clamps, coronary dilators, glasses frames, locomotor prostheses, arches for dental corrections, stents, brain spatulas;

- others: fire extinguishers, automatic sprinklers, pipe couplings, disassembly devices, automotive thermostats, filter holders, gas switches, solar actuators, steam valves, and vibration dampers.

\section{Mechanical fatigue phenomena at SMA}

The SMA from the construction of some installations is subjected to mechanical loads and also thermal loads. The SME supposes the existence of two structural states, with different mechanical 
properties, in reduced temperature frame $\left(\mathrm{cca} .15-30^{\circ} \mathrm{C}\right)$. Although in the two structural states (martensitic and austenitic), the alloy has certain properties of mechanical resistance, his basic function is to memorize. The loss of memory properties of the alloy, in certain conditions of loads, carries the names of amnesia. To keeping of the material integrity in load conditions is necessary the knowledge of the fatigue resistance both of the martensitic state and also the austenitic state. If the SMA element breaks during the load, then the fatigue resistance condition is not accomplished. In these conditions, the value of fatigue resistance will be smaller than the fatigue resistance values of the two structural states.

Mechanical fatigue resistance is defined through the minimal value of recovered deformation, after a certain number of usage cycles. Determining this size can be realized through different ways of loads, but the most precise is the stretching load. Considering that the shape memory properties are evaluated by the values of recovered deformation, this will be the function which characterizes the material. The basis method for results interpretation of the fatigue resistance is $\sigma(\mathrm{N})$ diagram, named Wohler curve, in which $\sigma$ represents the maximum amplitude of alternative load until breakage, after a certain number of cycles. This method can be applied to SMA, both in martensitic state and in austenitic state, characterizing the material resistance in the two states. The attempt consists in deformation in martensitic state at a determined value and its recovery through heating in austenitic domain, by an N number, as long as this value is kept. If the breakage is produced, the fatigue resistance condition is not accomplished. A cycle of fatigue load attempts must contain the following steps: (1) memory imprint at maximum limit or recovery deformation; (2) memory education through a number of cycles at maximum limit deformation; (3) demanding at tensions below the realization tension of memory deformation; (4) heating with the maintaining of the load tension; (5) cooling; (6) after a number of cycles, the recovered deformation value is measured. The diagram which contain variation curves of memory capacity according to the number of memory cycles and work load is presented in Figure 1.

There are many fatigue loading types according to the exploitation conditions.

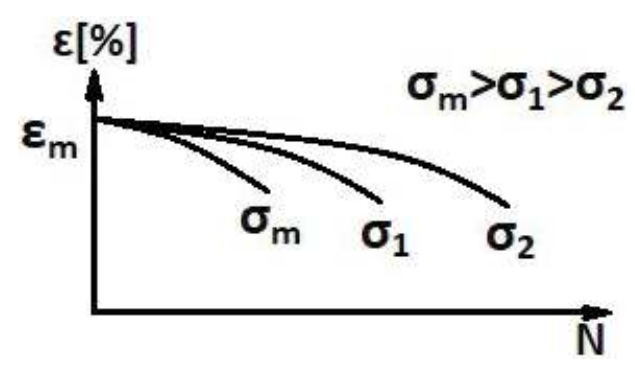

Figure 1. Fatigue under load diagram of $\mathrm{CuZnAl}$ alloy: $\varepsilon_{\mathrm{m}}-$ recovered deformation; $\sigma_{\mathrm{m}}-$ memory imprint load; $\sigma_{1}, \sigma_{2}-$ loading tensions. 


\section{Fatigue solicitation with free recovery of deformation}

This type of fatigue resistance property is guaranteed by the SMA producers. The function of these alloys being the recovered deformation and the variable is the number of memory cycles. If memory imprint deformation is higher, the recovery deformation is higher, but the number of exploitation cycles is reduced. The most encountered fatigue solicitation is solicitation with constant keeping of load during the test.

This type of load is found in the practice at a mechanical system with SMA element, which lifts a weight. The maximum load admitted is the one corresponding to the maximum memorized deformation. The value of free recovery deformation depends on the produced deformation in cold state (martensitic) and the constant load applied. The value of deformation produced by the constant load can be different throughout the test cycles.

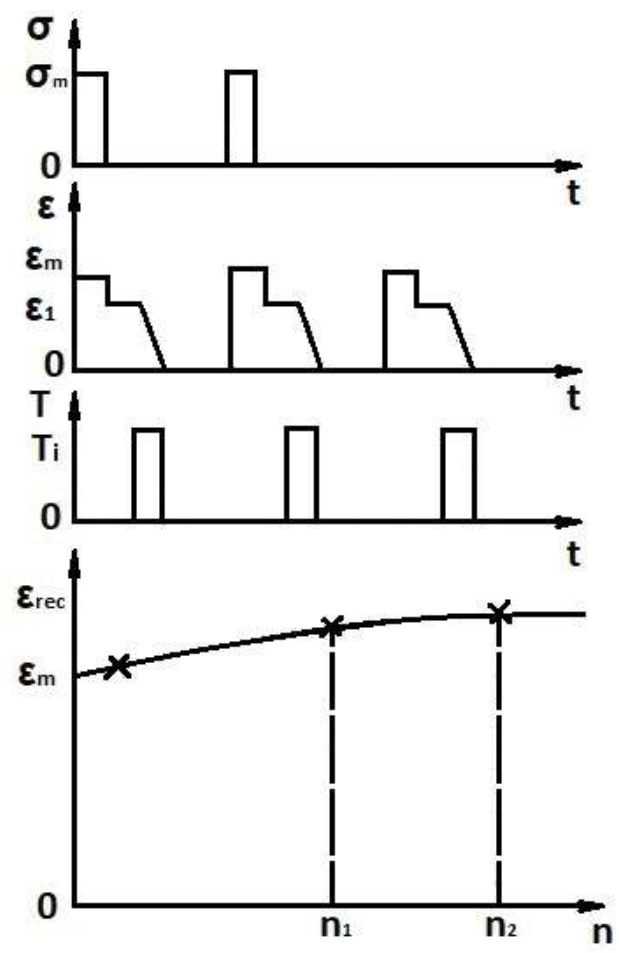

(a)

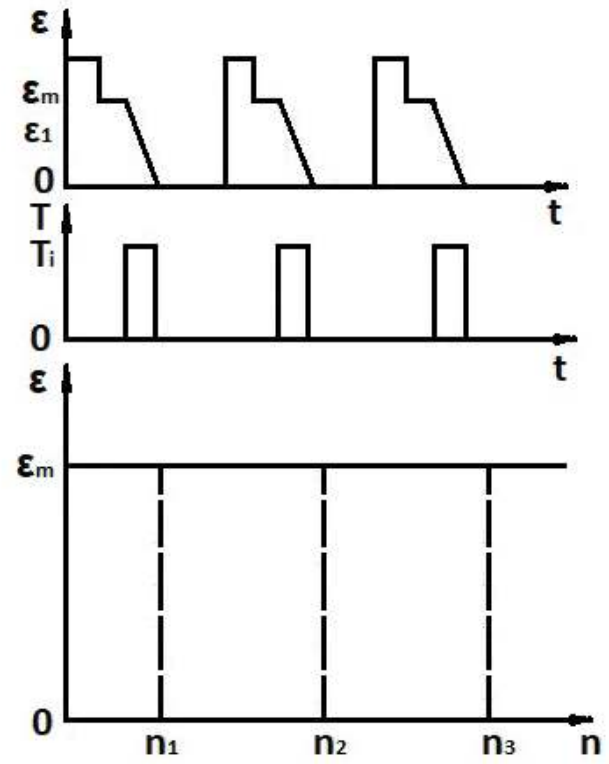

(b)

Figure 2. The graphic of fatigue test with constant load keeping (a) and constant deformation keeping (b): $\sigma_{\mathrm{m}}-$ load tension; $\varepsilon_{\mathrm{m}}-$ maximum memory deformation; $\varepsilon$-elastic recovery; $\mathrm{T}_{\mathrm{i}}-$ temperature of heating cycle; $\varepsilon_{\mathrm{rec}}-$ recovery deformation; $\mathrm{n}$-number of load cycles. 
The fatigue tests are proceeding at the determination of the maximum memory effect through traction and dilatometry, in order to establish both maximum load deformation, and also the corresponding tension of this deformation.

The establishment of the thermal cycle temperature is based on critical transformation temperatures. The test can be done on a specialized traction machine, provided with load and heat programmer. The test can be done at load or deformation values below the maximum memorizing value.

The grippers of sample in traction machine must allow the release adjustment of the sample with resulted remanent deformation, which is recovered through a later heating. From the diagram (Figure 2a), it results that every values are synchronized in time through repeating the fatigue test cycle.

In addition, solicitation at fatigue with constant keeping of deformation is found in the practice (Figure $\mathbf{2 b}$ ) at mechanical systems with memory element with contrast spring, with limiter. The admitted maximum value of deformation corresponded to maximum memorizing deformation.

\section{Solicitation at fatigue with recovery under load of recovery deformation}

Often, the SMA element from a device does not deform freely; it makes a mechanical work in memory recovery period. Because of that, the fatigue test with free recovery is not matching
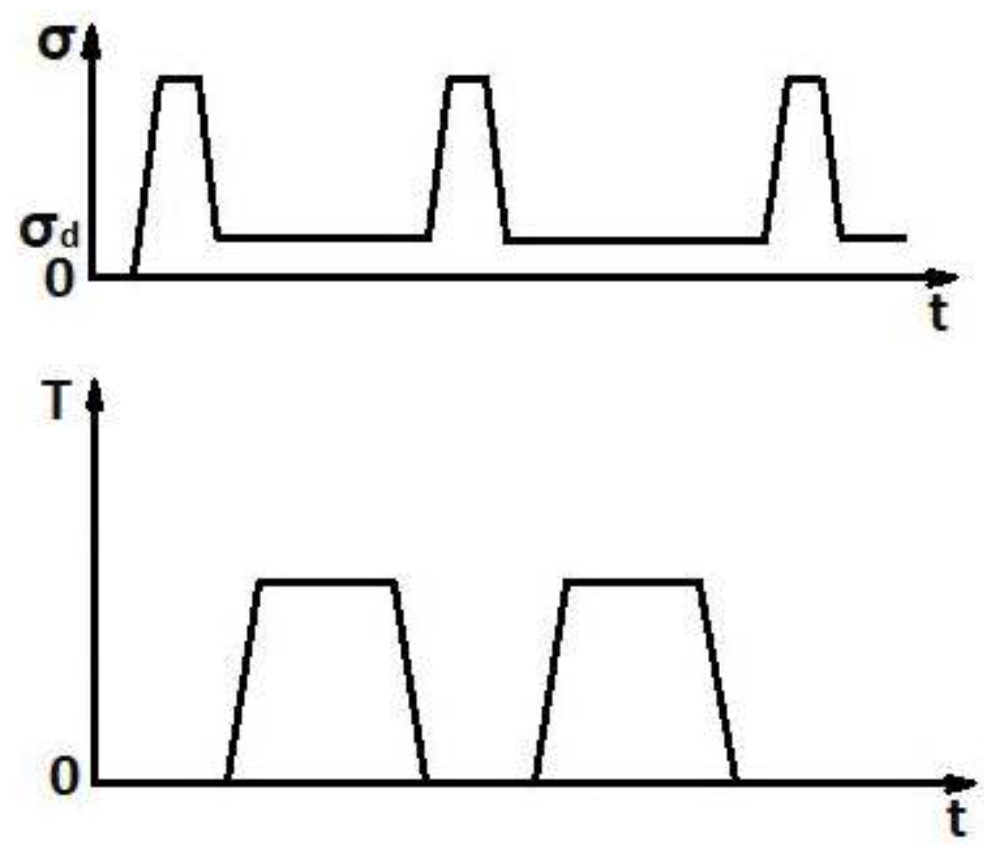

Figure 3. Load cycle $(\sigma)$ and thermal cycle $(\mathrm{T})$ for fatigue testing under load: $\sigma_{\mathrm{d}}-$ load in the time of shape recovery. 
with the exploitation conditions. For determination of fatigue resistance in these conditions, the traction machine must be provided with a special program for load cycle (Figure 3).

Imprint tension of the cold shape $(\sigma)$ must not exceed the maximum memory deformation, and the tension in the recovery period of the shape must be constant. The number of test cycles is determined after the sample breakage or after the loss a certain of memory capacity, determined through dilatometry. The determination involves a large number of samples and high volume of attempts. The graphic of fatigue resistance is compound from a family of curves.

Thermal fatigue represents the loss of some properties under the influence of a number of thermal cycles. In the case of SMA, the loss of memory properties is pursued. The application domain of thermal cycles must be contained in transformation critical points area, where the

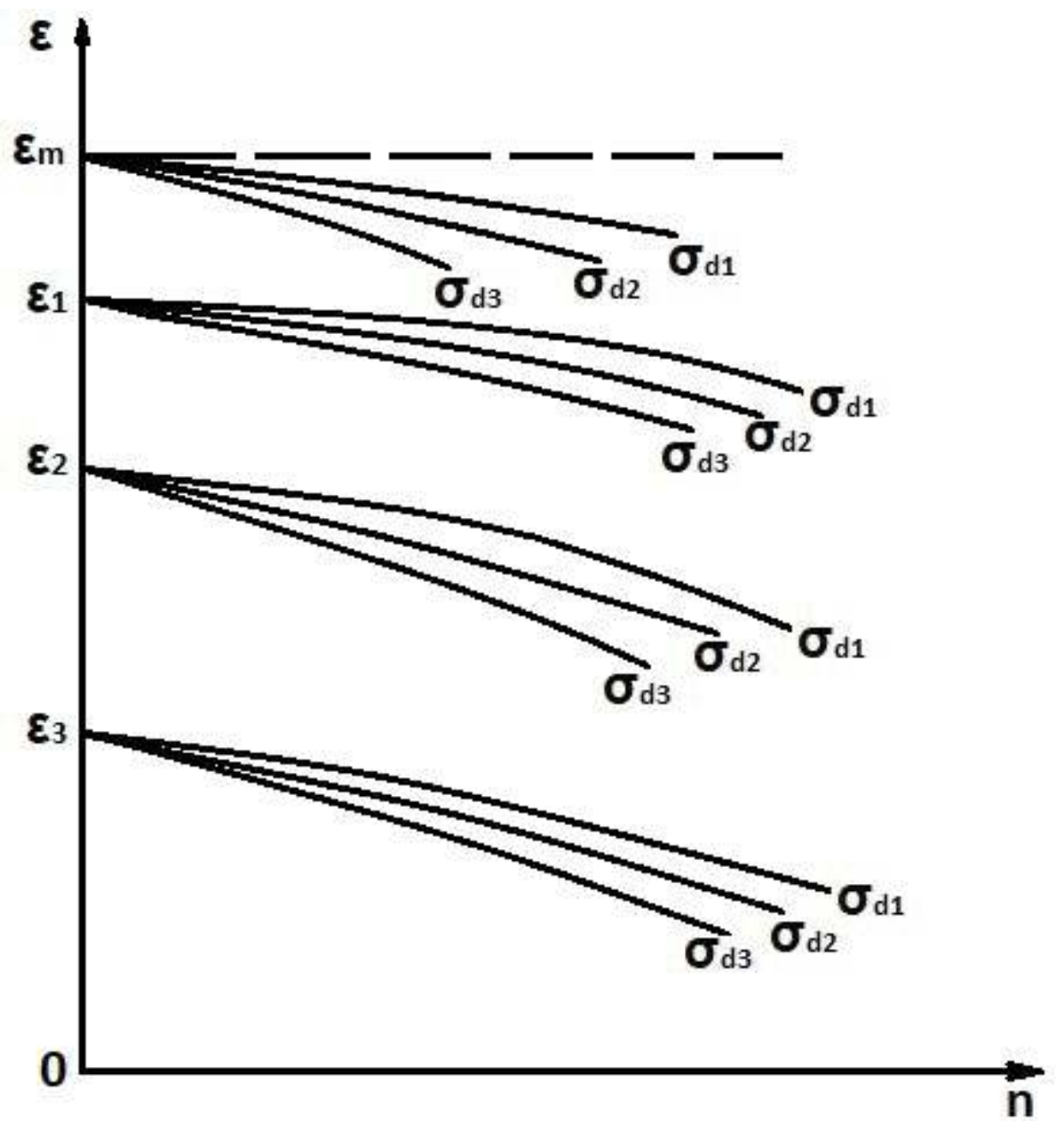

Figure 4. Graphic of fatigue test with recovery under load of deformation recovery. 


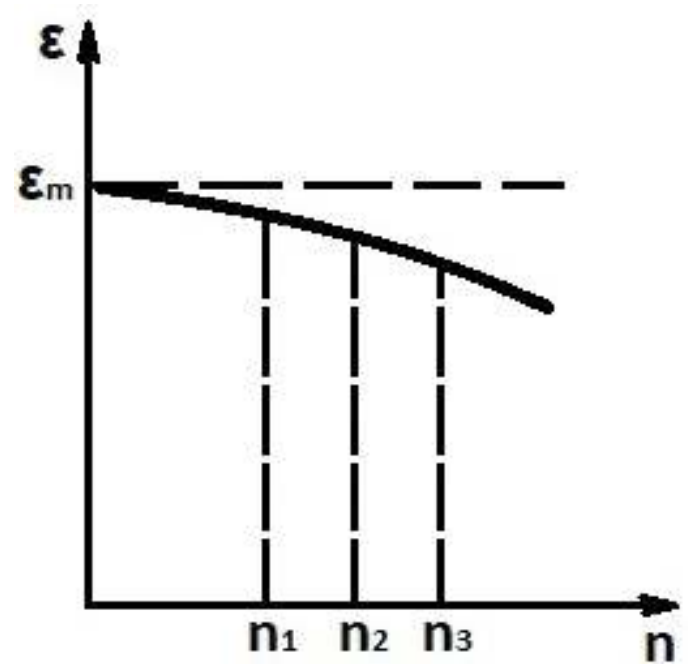

Figure 5. Diagram of thermal fatigue resistance.

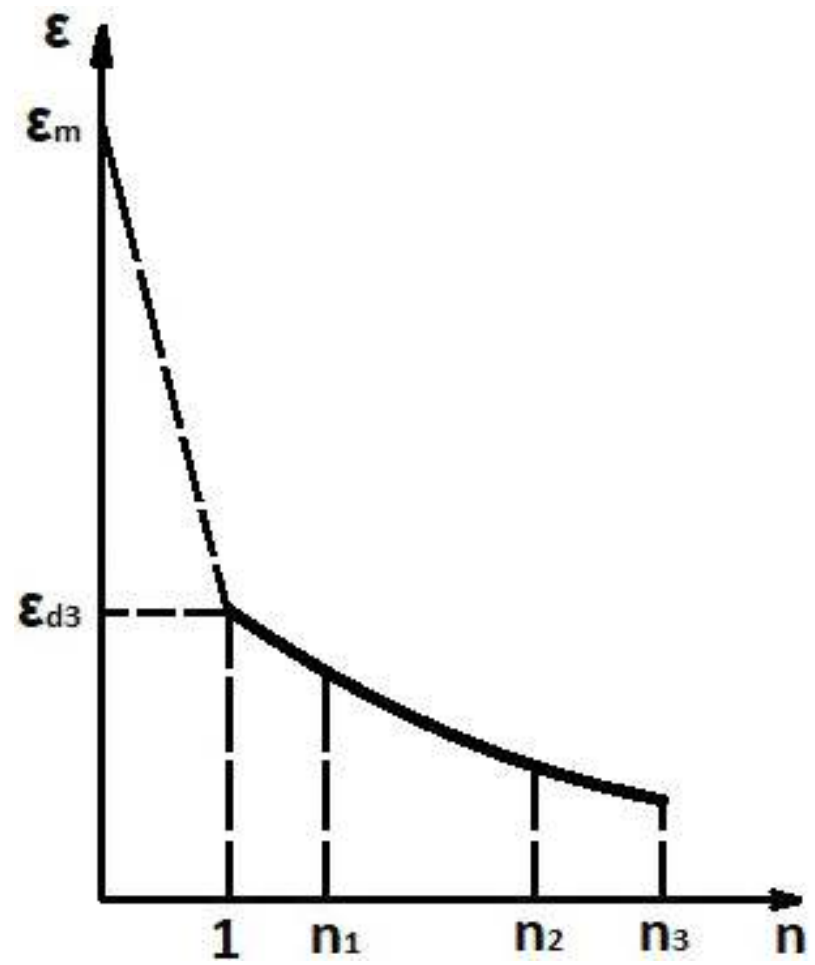

Figure 6. Thermal fatigue of the double sense memory component of a SMA: $\varepsilon_{\mathrm{ds}}-$ double sense recovery deformation. 
memory property manifests. The test for the determination of this property consists in determination of maximum recovery deformation, after a number of applied thermal cycles (Figure 3).

To determine the thermal fatigue of a SMA, a traction deformation $\left(\varepsilon_{\mathrm{m}}\right)$ is performed, after is subjected to a number heating and cooling cycles, without load, and then it is loaded to traction with the same deformation $\left(\varepsilon_{\mathrm{m}}\right)$ and is checked through thermal dilatometry the recovery deformation through heating (Figure 4).

Taking into account the precipitation produced through aging, the value of recovery deformation will decrease. At traction load for a remanent deformation $\left(\varepsilon_{\mathrm{m}}\right)$, the elastic recovery should be taken into account.

Depending on the number of points needed on the thermal fatigue diagram, a specific number of samples are subjected to thermal cycles. Then a sample is extracted and subjected to dilatometric test after a deformation $\left(\varepsilon_{\mathrm{m}}\right)$. Considering that the SMA has double sense component, a test of memory degradation through thermal fatigue (Figure 5) can be done.

For this purpose, the deformed sample with $\varepsilon_{\mathrm{m}}$ value is subjected to thermal cycles on dilatometer following the recovery deformation value without load (Figure 6).

The heating range of the heating cycle must contain the critical points. Through this method, it is measured the memory component from heating process through free recovery and the deformation component at cooling. To determine, this property is used a single sample.

\section{SMAs fatigue}

In the case of a device in which the memory element makes double sense shape memory effect (DSSME) in the system, fatigue resistance limit is defined through the number of cycles until the recovery load decreases at a minimum value (usually $70 \%$ from initial value).

SMA can present various phenomena of irreversible deterioration of microstructure and which define specific categories of fatigue. Therefore, in the case of conventional behavior and superelasticity, although there is a difference because of martensitic transformation induced under load, the same type of mechanical fatigue occurs. In the case of education through DSSME, if the applied load is maintained constantly, the fatigue phenomenon is thermal. In the case when the applied load is modifying SME, thermal-mechanical fatigue appears.

Mechanical fatigue involves breaking cracks in four stages: (1) defects accumulation; (2) cracks formation; (3) cracks propagation, in stationary and unsteady regime; (4) final breaking.

On the other hand, when more different SMAs, CuZnAl type, are mechanically educated at room temperature until the same load, was found that the alloys have the resistance to mechanical fatigue lower their Ms are lower. For SMAs, CuZnAl type, the resistance to mechanical fatigue is higher in a martensitic state. This fact is explained by the high fragility of austenite grains limits, that is a particularity of SMAs, CuZnAl type. 
To increase the resistance to mechanical fatigue, is applied a hot rolling, followed a quenching in water, through the grains limits gets an irregular shape. During mechanical education, this shape is recovering, absorbing an extra energy, thanks to which the tenacity of the limits is improved. The main method of enhancing the resistance at mechanical fatigue of SMA is grains finishing. The thermal fatigue is tied especially by the irreversible forming of defects, which leads to a considerable hardening in the case of a binary, biphasic brass (Cu- $40 \% \mathrm{Zn})$.

In the case of CuZnAl SMA, the mechanical education affects the critical temperatures of transformation, but in much lower ways than the thermal one. The influences of the two types of education are opposite, such that the thermal education strongly reduced the temperature hysteresis, and the mechanical education accentuate it, but very lightly.

Fatigue cracking is the phenomenon which leads to breakage at a repeated or fluctuating load, which is smaller than the elastic material load. Fatigue breaking is progressive, at the beginning there are small cracks, which increase under the action of fluctuant loads.

The place where the cracking begins is never extended at more than 2-5 grains around starting point [1]. The location of breaking beginning is dictated by the loads concentration and can be extremely diverse as a position and hard to distinguish in the successive stages of the propagation or increase cracking. The location of breaking beginning is placed in a parallel plan with the direction of shear load. At continuous repetitive loads, the cracks direction is changed perpendicular to the direction of elastic load. After which the initial crack is formed, it becomes a load concentrator, which tends to drive the crack deeper in metal with every repetition of load.

The local loads at the pick of the cracking are extremely high because the cracking and any open crack causes the deepening of the crack. The striations are really thin and it appears at a certain time and although they a certain shape, specific to the breakage through thermal fatigue. At the propagation of fatigue cracking, a continuous reducing of section area is observed, which weakens the material until in the end the breakage is complete. In the end, the breakage can be ductile or fragile or a combination between the two.

\section{Causes of properties degradation}

The SMAs are very sensitive at fatigue. In addition to the phenomena encountered at classic crystalline materials, the SMAs have additional mechanisms tied to phase change which characterized it. These mechanisms are regrouped in a way of thermal fatigue and three ways of mechanical fatigue, which are defined in Table 1.

In most of the applications, according temperatures, applied load, imposed deformation and $\mathrm{M}_{\mathrm{s}}$ transformation temperature, the various mechanisms which control the fatigue process are combined and the phenomenon becomes very complex.

Improving life and breaking of SMAs. The break type depends on the application mode of mechanical fatigue. At superelasticity, the break is generally intergranular. The improving life 
of these alloys imposes to reduce the internal tensions between grains and increasing their resistance to cracking.

To obtain these results, the following factors must be realized: (1) creating a rolling texture, which reducing the orientation differences between grains; (2) possibility to obtain of plastic deformation at grains limit level; (3) heat treatment to reduce the grains size and phase uniformization of structure; (4) decreasing of the martensite plates (Table 2).

Regarding the standard chemical composition and the values of specific mechanical characteristics of SMAs, Cu-based alloy, little information is found. Some specific conditions to obtain SMAs are distinguishing: (1) chemical compositions which variants between very tied limits; (2) obtaining of alloy from high purity components with very strict limitation of impurities; (3) low physical and chemical anisotropy in the alloy volume, and (4) optimal correlation of elaboration and thermal-mechanical treatment parameters. Most of the SMAs obtaining method contain three steps: (1) elaboration-forging; (2) primary heat treatment; (3) obtaining of hot and cold shapes.

Analyzing (1) SMAs types, (2) shape memory properties, and (3) obtaining costs were chosen for the study of the thermo-mechanical fatigue on Cu-based alloys. Between the Cu-based alloys, $\mathrm{CuZnAl}$ types were chosen, that is, $\mathbf{C u}_{\mathbf{7 5}} \mathbf{Z n}_{\mathbf{1 8}} \mathbf{A l}_{\mathbf{6}}$.

The thermal-mechanical fatigue phenomenon of SMA cannot be avoided. Although in the two structural states (martensite and austenite), the alloy has certain properties of mechanical

\begin{tabular}{llll}
\hline Fatigue & $\mathbf{T}<\mathbf{M}_{\mathbf{f}}$ & $\mathbf{A}_{\mathbf{f}}<\mathbf{T}<\mathbf{M}_{\mathbf{s}}$ & $\mathbf{T}>\mathbf{M}_{\mathbf{s}}$ \\
\hline Mechanical & $\begin{array}{l}\text { Reorient of martensite } \\
\text { variants }\end{array}$ & $\begin{array}{l}\text { Martensite formation through } \\
\text { contraction }\end{array}$ & $\begin{array}{l}\text { Classic fatigue in austenitic } \\
\text { state }\end{array}$ \\
Thermal & Thermal education in stability & domain of the two phases & \\
\hline
\end{tabular}

Table 1. Ways of thermal and mechanical fatigue at SMA.

\begin{tabular}{lllll}
\hline Solicitation cycles & CuZnAl & NiTi & CuAlNi & Monocristalyne \\
\cline { 4 - 5 } & & & Policristalyne & $150 \mathrm{MPa}$ \\
$\mathrm{s}^{\max }\left(\mathrm{N}=10^{5}\right.$ cycles $)$ & $75 \mathrm{MPa}$ & $250 \mathrm{MPa}$ & $100 \mathrm{MPa}$ & $10 \%$ \\
$\mathrm{e}^{\max }$ simple effect & $4 \%$ & $8 \%$ & $5 \%$ & $6 \%$ \\
$\mathrm{~N}=10^{3}$ & $2 \%$ & $3 \%$ & $3 \%$ & $4 \%$ \\
$\mathrm{~N}=10^{4}$ & $1 \%$ & $2 \%$ & $2 \%$ & - \\
$\mathrm{e}^{\max }$ double effect & $2 \%$ & $5 \%$ & $2 \%$ & - \\
$\mathrm{N}=10^{2}$ & $1 \%$ & - & $1.2 \%$ & - \\
$\mathrm{N}=10^{3}$ & $0.8 \%$ & $1 \%$ & $0.8 \%$ & \\
\hline $\mathrm{s}^{\text {max }}-$ maximum load; $\mathrm{e}^{\text {max }}-$ maximum effect; $\mathrm{N}-$ cycles number of load. & \\
\hline
\end{tabular}

Table 2. Values of fatigue resistance coefficients. 
resistance, its basic function is memorizing. The fatigue resistance will consider the loss of the memorizing capacity in cyclic load conditions.

The equipment used for testing the resistance at mechanical fatigue, reproduces the loads at which are subjects the parts in exploitation. The equipments used for testing the resistance at thermal fatigue study the modifications that appear in a sample subjected to a thermal load (heating-cooling).

The study of optimal exploitation time of an parts made from SMAs is necessary for the knowledge of the exploitation time in maximum parameters. This study proposes the necessity to realize thermal and mechanical combined loads for fatigue tests. The samples for the tests are samples with standard dimensions and will be subjected to traction, being caught between grippers. The samples load is made by mechanical means (Figure 7).

According to the weights attached to lever system, the sample will be loaded with a load directly proportionally with the weight placed $(4.5 \mathrm{~kg})$. The proportionality is obtained through a lever system. The alloy has certain mechanical resistance properties, which can be altered through fatigue in cyclic exploitation conditions. The sample will be heated and cooled cyclic, in $40-150^{\circ} \mathrm{C}$ temperatures interval, with an installation which blow hot or cold air. The heating time is $4 \mathrm{~min}$ and cooling time is $2 \mathrm{~min}$. The cycle's number $(\mathrm{N})$ needed for a sample is $10^{3}-10^{4}$ cycles, and the exploitation time for realizing of these cycles is in the order of tens of hours.

An important problem of this installation is the synchronization of thermal cycle with mechanical cycle, an important fact in the case of SMAs and the study of their thermal-mechanical fatigue phenomenon.

The prototype installation for thermal-mechanical fatigue tests (Figure 8) respect the principles of functioning for testing installation at mechanical and thermal fatigue. The control of parameters and result recording are made automatically with computer and XMEM original software.

1. Elaboration of shape memory alloy

Elaboration is a first step in obtaining process of shape memory alloy. The elaboration procedures are different according to the alloy type or the tracked properties. The alloy elaboration was made in an induction furnace, with graphite crucible (Figure 9a), using high purity alloying elements.

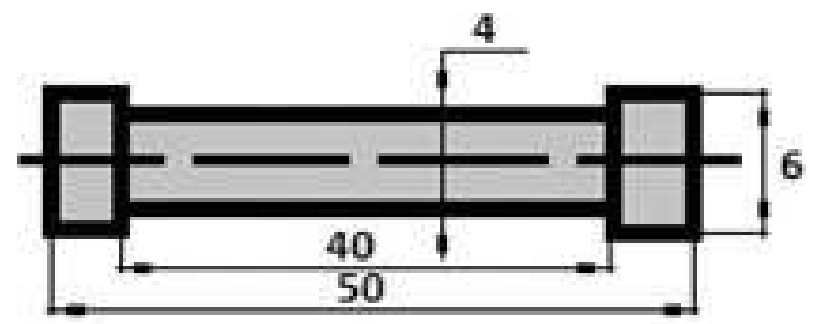

Figure 7. Shape and dimensions of samples used for experiments. 


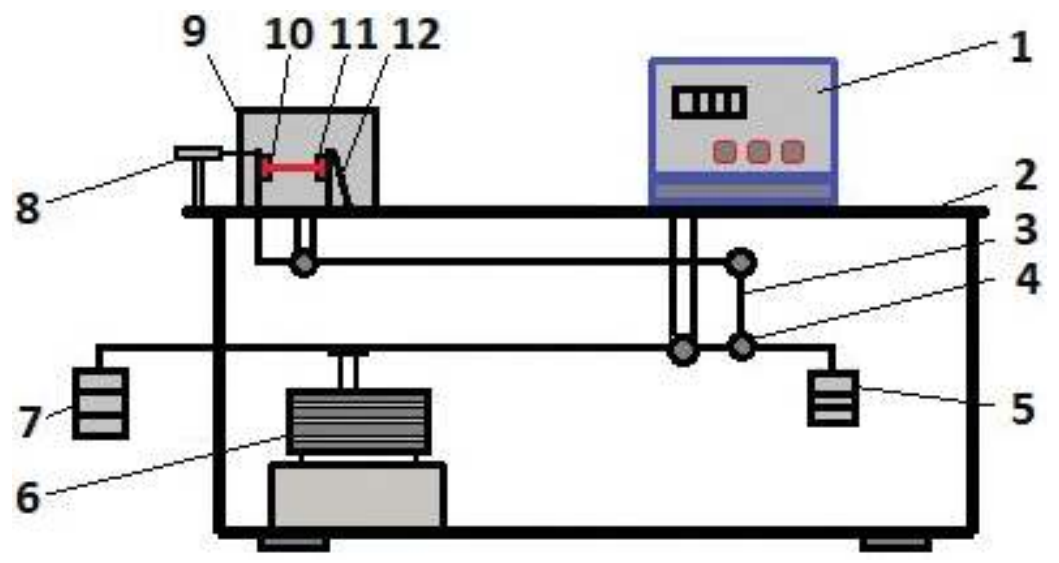

Figure 8. The prototype installation for thermal-mechanical fatigue tests. (1) control panel; (2) rigid metallic frame; $(3,4)$ bearings and levers system for mechanical load; (5) counter-weight; (6) motor-reducing gear-arm assembly for lift the weights; (7) weights; (8) comparator watch; (9) heating enclosure housing; (10) SMA test sample; (11) grippers; (12) fixed fastening system.

At elaboration temperature, the interaction between metallic charge and furnace atmosphere consist from oxidation reactions or gases dissolution. The elaboration stages are the following: (1) copper introducing in crucible; (2) after copper melting, aluminum adding; (3) zinc adding.

The melting temperature is limited to $1200^{\circ} \mathrm{C}$ to reduce the evaporation losses. There is a risk of zinc burning and dissolution of resulted gases in the metallic bath. The protection of metallic bath against oxidation was made with borax $\left(\mathrm{Na}_{2} \mathrm{~B}_{4} \mathrm{O}_{7}\right)$.

After homogenization of alloy in graphite crucible (Figure 9a), heating in induction furnace with high frequencies $(8000 \mathrm{~Hz}$ ), the alloy is casted in a metallic die (Figure $9 \mathbf{b}$ ) and was obtained the samples (Figure 9c).

2. Experimental determination of chemical composition

The analysis of chemical composition on cast samples was made on Foundry Masters spectrometer, 01 J0013 type [4]. With WASLAB software and the extensible calibration programs, is obtained an analysis bulletin, which present the determined values (Table 3).

Through the quantitative spectral analysis, we want to have the certainty that the resulted percentages of alloying elements from sample are in the limits imposed for charge. In the calculation of charge was considered that impurifying elements exist: Fe (0.021-0.033), Co (<0.015), Si (0.009-0.026), Ni (<0.005), Ag (0.002), As (0.008-0.01), Mn (0.02-0.08).

\section{Diffractometric analysis of sample in cast state}

The diffractometric analysis was made on X-ray diffractometer, XPert Pro Philips Analytical type [5]. The obtained results are presented in Figure 10. 


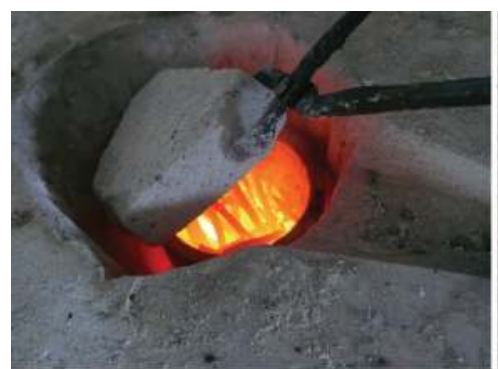

(a)

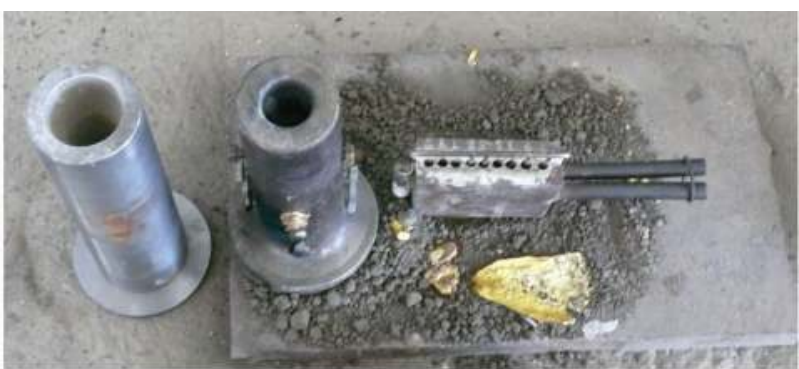

(b)

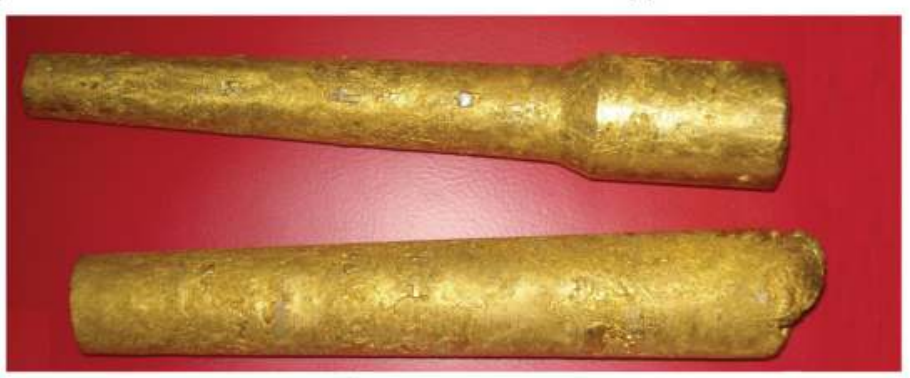

(c)

Figure 9. (a) Graphite crucible; (b) metallic dies for SMA casting; (c) cast samples.

\begin{tabular}{llllllllll}
\hline $\mathbf{C u}^{*}$ & $\mathrm{Zn}^{*}$ & $\mathrm{Al}^{*}$ & Fe & Co & Si & Ni & Ag & As & Mn \\
\hline 75.4 & 18.6 & 5.85 & 0.021 & 0.015 & 0.026 & 0.005 & 0.002 & 0.008 & 0.073 \\
\hline
\end{tabular}

${ }^{*}$ Conventional notation of studied alloy $-\mathrm{Cu}_{75} \mathrm{Zn}_{18} \mathrm{Al}_{6}$.

Table 3. Chemical composition (\%).

The presence of chemical compounds is distinguished with the formula:

- copper-zinc $\mathrm{Cu}_{5} \mathrm{Zn}_{8}$ in $53 \%$

- $\quad$ aluminum-copper $\mathrm{Al}_{4} \mathrm{Cu}_{9}$ in $47 \%$

4. Structural analysis of sample in cast state through optical and SEM microscopy

Optical analysis of microstructure for studied alloy was made on a metallographic microscope, AxioObserver D1m type [7]. The SEM microscopy was made on VEGA II LSH microscope, which was coupled with EDX detector, QUANTAX QX2 type [8].

The $\mathrm{Cu}_{75} \mathrm{Zn}_{18} \mathrm{Al}_{6}$ alloy presents various types of martensite, with parallel plates, zig-zag and arrow heads (Figures 11 and 12). 


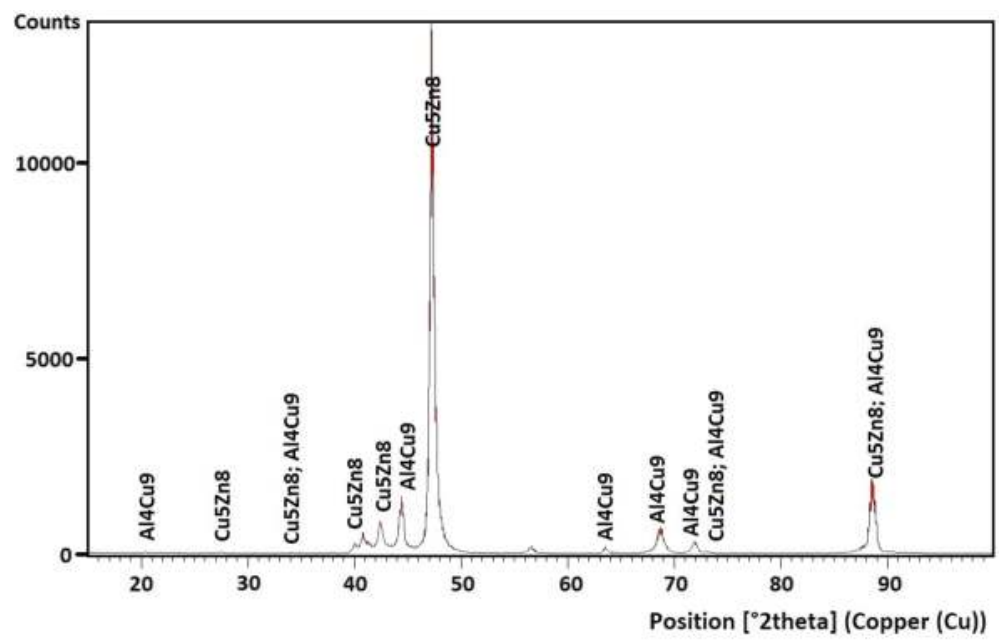

Figure 10. Chemical compounds distribution for $\mathrm{Cu}_{75} \mathrm{Zn}_{18} \mathrm{Al}_{6}$ alloy, in cast state.

\section{Thermal conductivity analysis of cast sample}

The measurements of thermal conductivity were made because the SMAs are used in applications like actuators, fact which impose the correct establish of the values for this coefficient and his mode by electric activation. TCi system [6] determines directly the thermal conductivity and other parameters, for different types of materials: solids, liquids, powders, foams. The achieved analyses are nondestructive, and for tests they are necessary small samples (Table 4).

The $\mathbf{C u}_{75} \mathbf{Z n}_{18} \mathbf{A l}_{6}$ alloy present a good thermal conductivity in cast state, the medium value is fit in the limits which are specific to the copper alloys casted in parts.

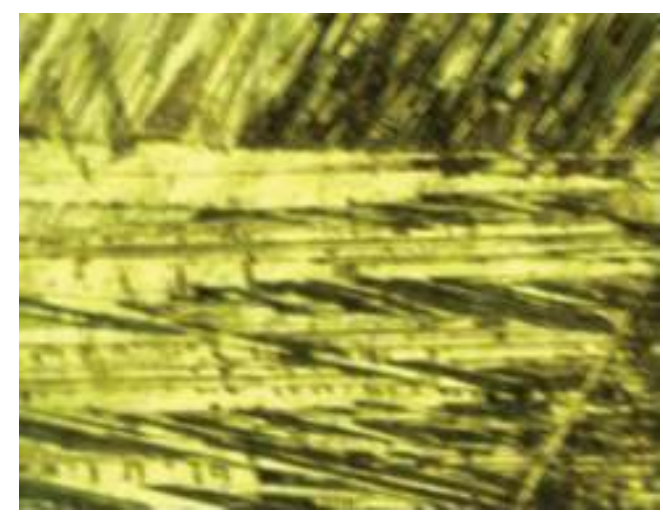

Figure 11. Optical microscopy, cast state, $\mathrm{HNO}_{3} 30 \%$ attack, $(100 \times)$. 


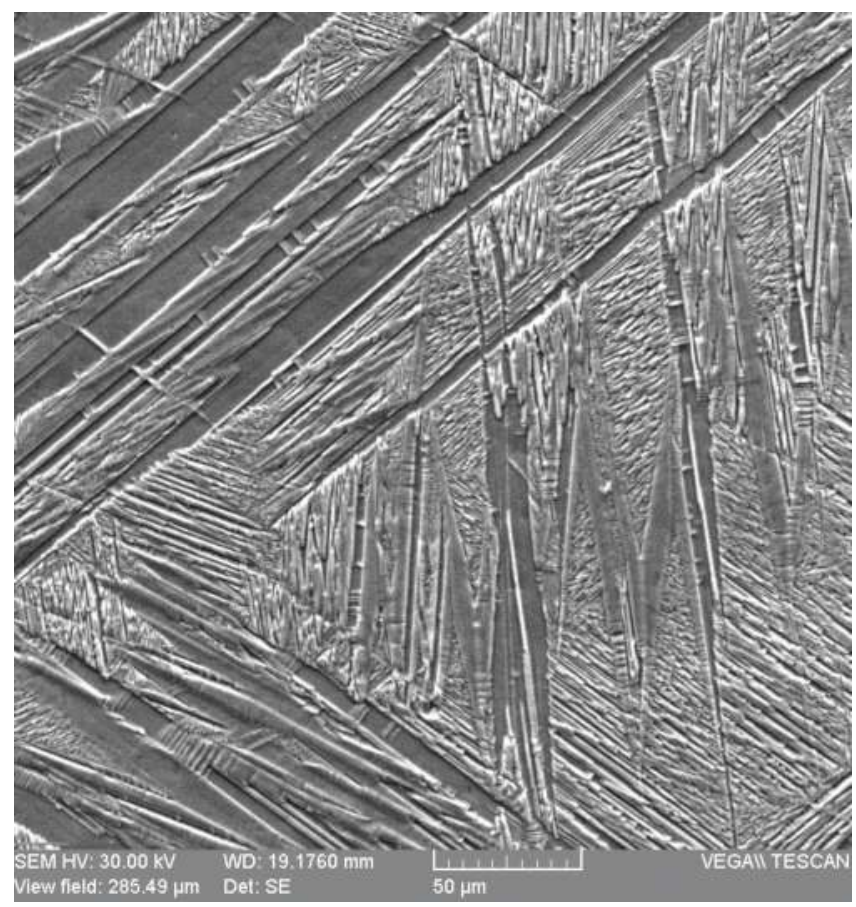

Figure 12. SEM microscopy, cast state, $\mathrm{HNO}_{3} 30 \%$ attack, $(1000 \times)$.

\begin{tabular}{|c|c|c|c|c|c|c|c|c|c|c|}
\hline No. & 1 & 2 & 3 & 4 & 5 & 6 & 7 & 8 & 9 & 10 \\
\hline $\begin{array}{l}\text { Thermal conductivity } \\
(\mathrm{W} / \mathrm{m} \cdot \mathrm{K})\end{array}$ & 43.900 & 41.140 & 40.450 & 40.650 & 40.300 & 40.310 & 40.950 & 40.850 & 41.050 & 41.050 \\
\hline Caloric capacity (J/kg.K) & 437.750 & 438.040 & 438.059 & 438.059 & 438.058 & 438.058 & 438.054 & 438.056 & 438.051 & 438.052 \\
\hline
\end{tabular}

Table 4. Thermal conductivity for sample in cast state.

\section{Hot plastic deformation}

For structure finishing, the cast samples are subjected to a hot plastic deformation. The heating temperatures for plastic deformation is $850 \pm 10^{\circ} \mathrm{C}$, with maintain period by $0.5 \mathrm{~h} / 25 \mathrm{~mm}$ thickness of material, to ensure a mono-phasic structure.

The plastic deformation was made in $850-800^{\circ} \mathrm{C}$ thermal interval, what is means the obtaining of deformation grade through repeating the plastic deformation operation (10-20 cycles). Figure $13 \mathrm{c}$ presents the forged sample during plastic deformation.

7. Diffractometric analysis of sample in forged state (Figure 14)

The presence of chemical compounds is distinguished with the formula: 


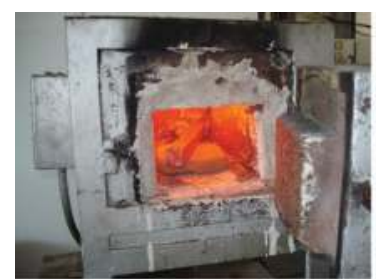

(a)

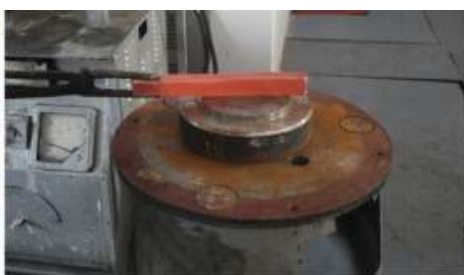

(b)

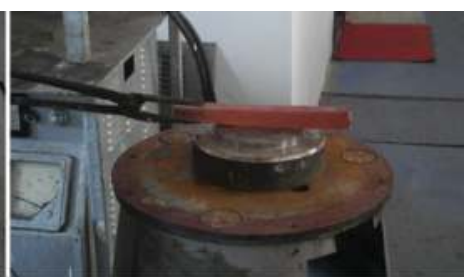

(c)

Figure 13. (a) Heating furnace and forged parts; (b) forging of cast; (c) hot forged sample $\left(850-900^{\circ} \mathrm{C}\right)$.

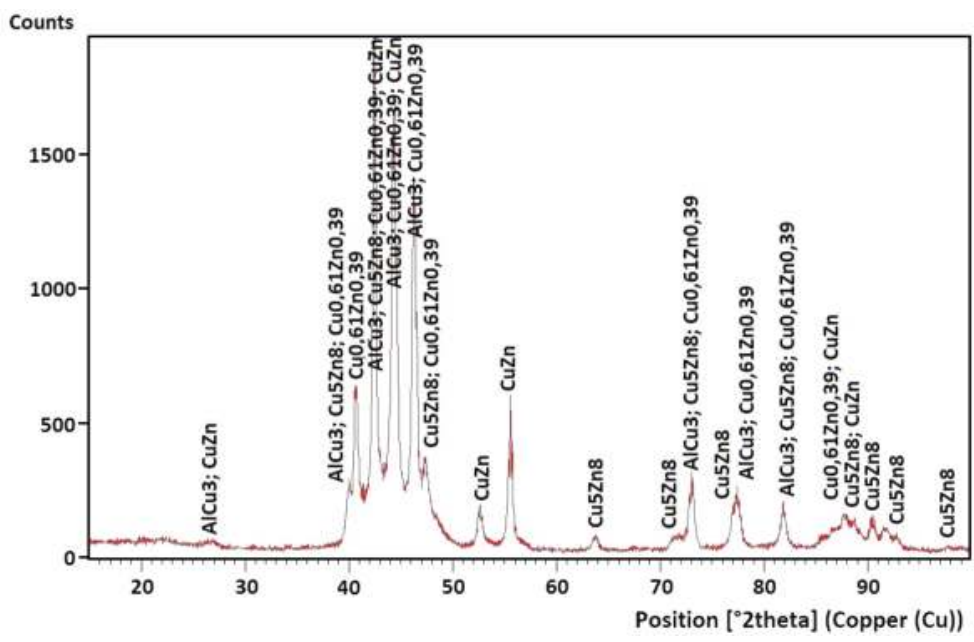

Figure 14. Chemical compounds distribution for $\mathbf{C u}_{75} \mathbf{Z n}_{18} \mathbf{A l}_{6}$ alloy, in a forged state.

- aluminum-copper $\mathrm{AlCu}_{3}$ by $20.5 \%$

- copper-zinc $\mathrm{Cu}_{5} \mathrm{Zn}_{8}$ by $33.3 \%$

- $\alpha-\mathrm{Cu}_{0.61} \mathrm{Zn}_{0.39}$ by $25.6 \%$

- $\quad$ copper-zinc CuZn by $20.6 \%$

8. Structural analysis of sample in forged state through optical and SEM microscopy (Figures 15 and 16)

The same martensitic structure, mixed, with different shapes: parallel plates, arrow head, is found and also in the case of forged sample.

9. Thermal conductivity analysis of samples in forged state (Table 5)

The hot plastic deformation has a lower influence on thermal conductivity; the measured values are falling in specific limits of SMA, based on cooper, found in different stages of processing through plastic deformation and obtaining of parts. 


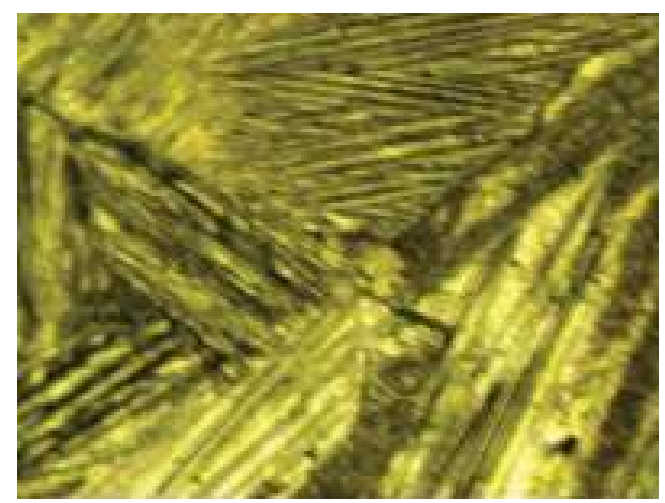

Figure 15. Optical microstructure, in forged state, $\mathrm{HNO}_{3} 30 \%$ attack, $(100 \times)$.

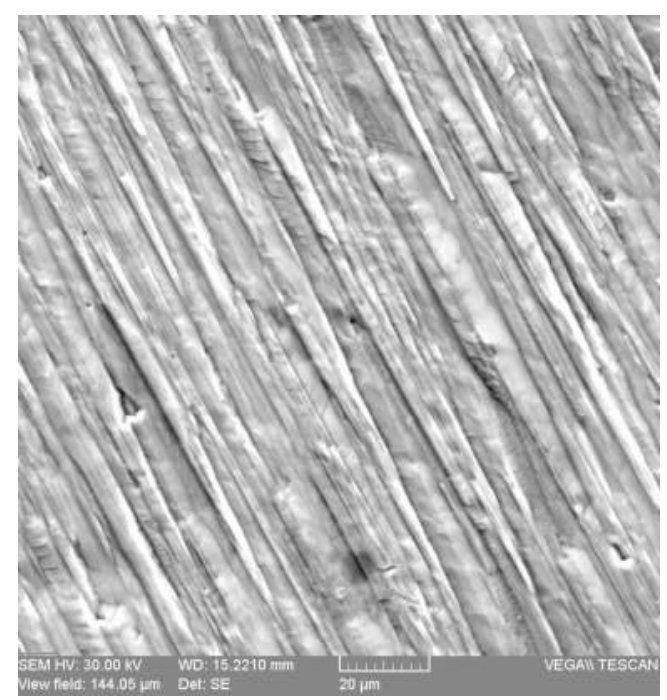

Figure 16. SEM microstructure, in forged state, $\mathrm{HNO}_{3} 30 \%$ attack, $(5000 \times)$.

\begin{tabular}{|c|c|c|c|c|c|c|c|c|c|c|}
\hline$\#$ & 1 & 2 & 3 & 4 & 5 & 6 & 7 & 8 & 9 & 10 \\
\hline $\begin{array}{l}\text { Thermal conductivity } \\
(\mathrm{W} / \mathrm{m} \cdot \mathrm{K})\end{array}$ & 39.289 & 37.880 & 37.121 & 36.883 & 36.492 & 36.588 & 36.225 & 35.968 & 36.015 & 35.444 \\
\hline Caloric capacity $(\mathrm{J} / \mathrm{kg} \cdot \mathrm{K})$ & 438.015 & 437.853 & 437.713 & 437.662 & 437.569 & 437.592 & 437.500 & 437.428 & 437.442 & 437.268 \\
\hline
\end{tabular}

Table 5. Thermal conductivity for sample in forged state.

10. Heat treatment of quenching to put in solution

The forged samples were processed through machining at standard dimensions according to the experimental tests. These samples are subjected to quenching heat treatment. The 
parameters of heat treatments are the following: (1) heating with furnace until $800^{\circ} \mathrm{C}$; (2) maintaining for temperature uniformization and finishing the structural transformation, for an hour; (3) rapid cooling in water at ambiance temperature (Figures 17 and 18).

11. Diffractometric analysis of sample in quenched state

The presence of chemical compounds is distinguished with the formula:

- aluminum-copper $\mathrm{AlCu}_{3}$ by $42.8 \%$

- $\quad$ copper-zinc $\mathrm{Cu}_{5} \mathrm{Zn}_{8}$ by $51.2 \%$

12. Structural analysis of quenched sample through optical and SEM microscopy

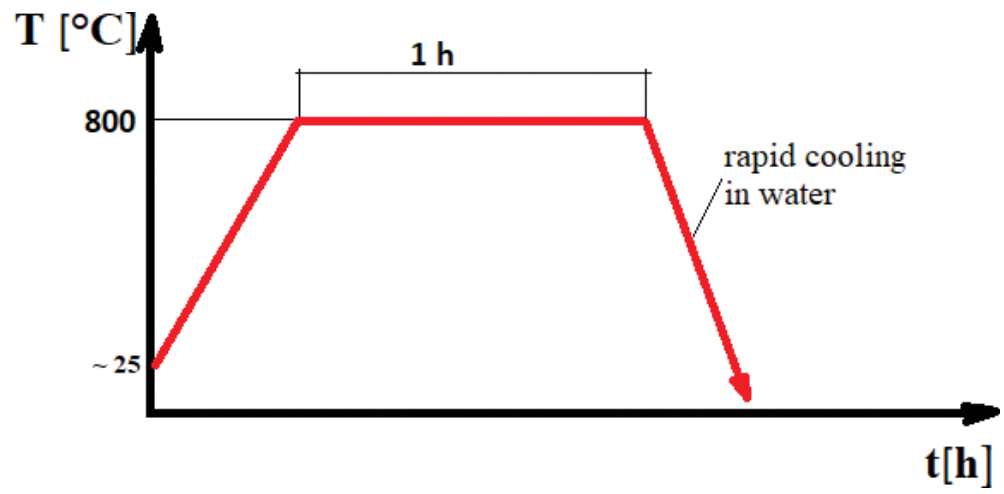

Figure 17. Primary heat treatment: quenching to put into solution.

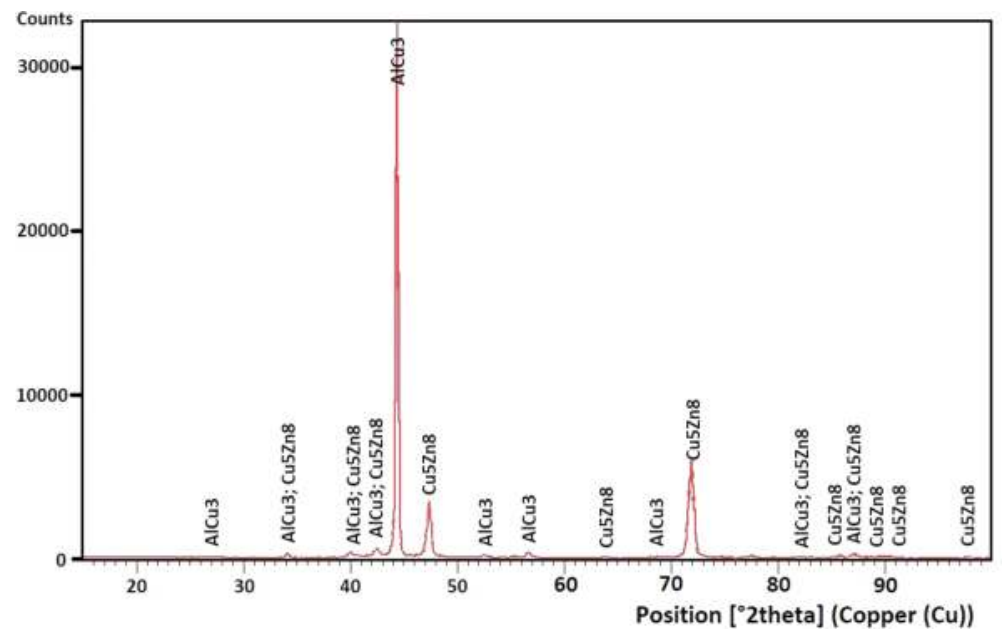

Figure 18. Chemical compounds distribution for $\mathrm{Cu}_{75} \mathbf{Z n}_{18} \mathbf{A l}_{6}$ alloy, in quenched state. 
The martensitic structure from quenched sample is present, having predominantly the shape of arrow head (Figure 19).

13. Thermal conductivity analysis of sample in quenched state (Table 6)

The decrease of thermal conductivity for quenched sample more than six times over cast sample or forged sample, transform the SMA in a thermal barrier, following in the heatingcooling process, the stored energy to be used in DSSME goal.

14. Induction of SME-deformation with imposed elongation

After the heat treatment, the samples were subjected to an elongation with 3\% deformation grade (Figure 20). The controlled elongation was realized on a traction machine, Instron 3382 model [2] (Table 7) (Figure 21).

\section{Checking of SME through dilatometric analysis}

The dilatometric analysis records the length modifications for a sample, when it is exposed to a temperature variation. This modification of length can be reversible. Through dilatometric analysis can determine the transformation points in solid states, specific to the analyzed alloy. The determination of these transformation points is important for the applications in which are used parts from SMA, Cu-based.

The dilatometric analysis of $\mathrm{Cu}_{75} \mathrm{Zn}_{18} \mathrm{Al}_{6}$ alloy was made on a differential dilatometer, Linseis L75H/1400 model [3]. In the heating time, with a constant heating rate $\left(5^{\circ} \mathrm{C} / \mathrm{min}\right)$, the alloy

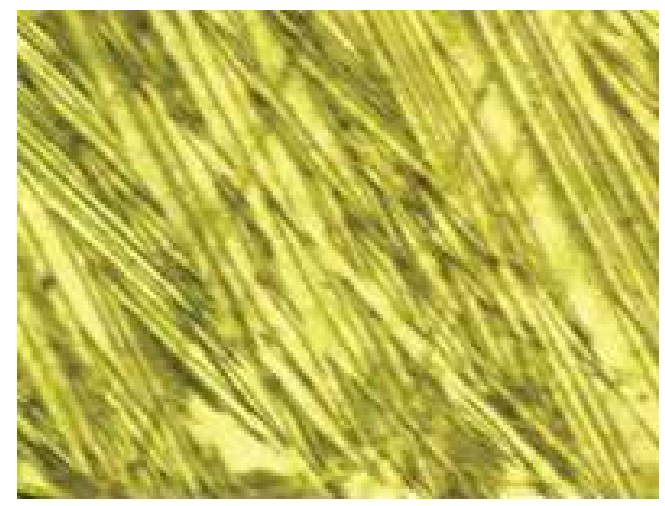

Figure 19. Optical microstructure, in quenched state, $\mathrm{HNO}_{3} 30 \%$ attack, $(100 \times)$.

\begin{tabular}{lllllllllll}
\hline$\#$ & $\mathbf{1}$ & $\mathbf{2}$ & $\mathbf{3}$ & $\mathbf{4}$ & $\mathbf{5}$ & $\mathbf{6}$ & $\mathbf{7}$ & $\mathbf{8}$ & $\mathbf{9}$ & $\mathbf{1 0}$ \\
\hline $\begin{array}{l}\text { Thermal conductivity } \\
(\mathrm{W} / \mathrm{m} \cdot \mathrm{K})\end{array}$ & 6892 & 6613 & 6407 & 6333 & 6211 & 6142 & 6324 & 6265 & 6179 & 6178 \\
$\begin{array}{l}\text { Caloric capacity (J/kg.K) } \\
4\end{array}$ & 403.249 & 404.328 & 405.291 & 405.673 & 406.355 & 406.766 & 405.722 & 406.045 & 406.543 & 406.551 \\
\hline
\end{tabular}

Table 6. Thermal conductivity of sample in quenched state. 


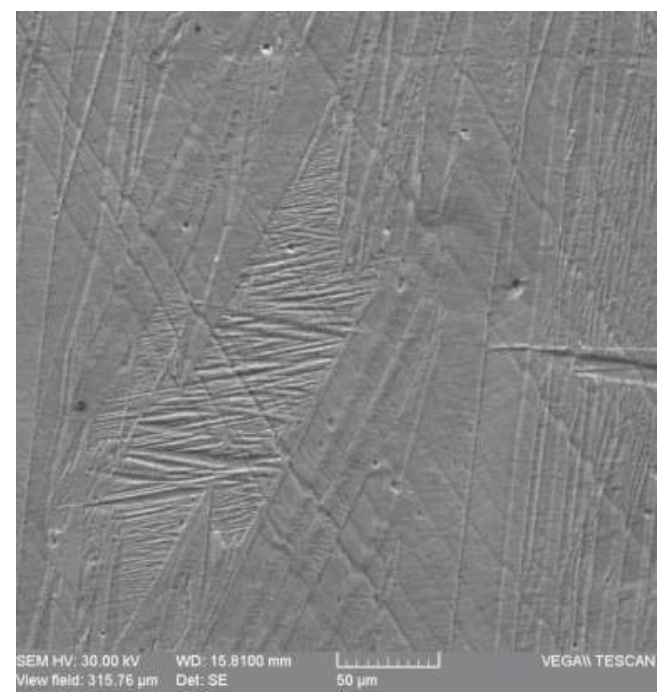

Figure 20. SEM microstructure, in quenched state, $\mathrm{HNO}_{3} 30 \%$ attack, $(1000 \times)$.

\begin{tabular}{llll}
\hline Maximum force $F_{\max }(\mathrm{N})$ & Young modulus E $(\mathrm{MPa})$ & Maximum load $\sigma_{\mathbf{r}}(\mathrm{MPa})$ & Elongation $(\%)$ \\
\hline 3576.16 & 20908.02 & 284.58 & 3
\end{tabular}

Table 7. Mechanical characteristics.

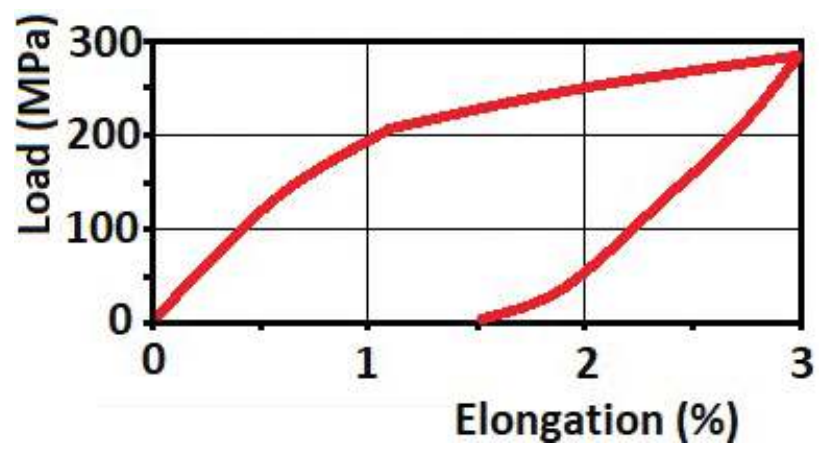

Figure 21. Load-elongation diagram.

presents a contraction phenomenon which starts at the start temperature of martensite-austenite transformation and finishes when the alloy does not present a martensitic structure (Figure 22).

The $\mathbf{C u}_{75} \mathbf{Z n}_{18} \mathbf{A l}_{6}$ alloy presents the martensite-austenite transformation domain between $65.8^{\circ} \mathrm{C}$ and $102.2^{\circ} \mathrm{C}$. The maximum contraction, between two temperature values, is $30.7 \mu \mathrm{m}$. 


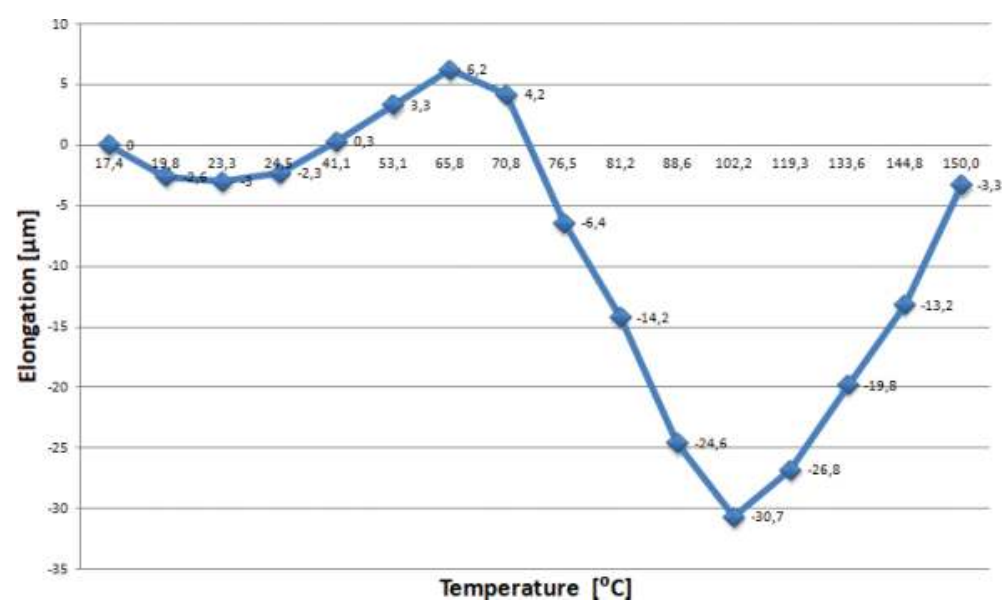

Figure 22. Sample dilatogram, after quenching to put in solution and controlled deformation (3\% grade), without fatigue cycles.

\section{Thermal-mechanical fatigue of $\mathrm{Cu}_{75} \mathrm{Zn}_{18} \mathrm{Al}_{6}$ alloy}

\subsection{Testing conditions}

The samples (Figure 7) used for thermal-mechanical fatigue tests are falling in dimensional class of samples which can be used for dilatometric analysis (10-50 mm length, 3-6 mm diameter). The experiments were made on a prototype installation (Figure 8), designed and special manufactured for these tests. After education, the samples were subjected to a variable number of thermal-mechanical fatigue cycles.

After a certain number of cycles, the samples were analyzed on dilatometer, studying the contraction modifications on the heating time and the variation of temperatures domain for the critical points. With a hot/cold air installation (constructive element from prototype installation), the $\mathbf{C u}_{75} \mathbf{Z n}_{18} \mathbf{A l}_{6}$ sample is heating up to $150^{\circ} \mathrm{C}$, and then cooled until $40^{\circ} \mathrm{C}$. The heating rate is $15^{\circ} \mathrm{C} / \mathrm{min}$, and cooling rate is $30^{\circ} \mathrm{C} / \mathrm{min}$.

The control of testing parameters (heating and cooling parameters, number of cycles, test times) was made with specific software, XMEM. The load to which it was subjected the sample is kept constant for all the thermal-mechanical fatigue tests. Also with XMEM software, was made and synchronization of mechanical load cycle with thermal cycle: when the sample is mechanical loaded, is started the heating. The sample stays under load during the heating time, up to $150^{\circ} \mathrm{C}$ final temperature. After this moment, the sample is cooled, and the mechanical load is removed, using motor-reducing gear-arm system to lift the weights (Figure 8). While the mechanical load is canceled, the sample is cooling until $40^{\circ} \mathrm{C}$ final temperature. 


\subsection{Experimental results}

After an arbitrary number of thermal-mechanical fatigue cycles, the sample is analyzed on dilatometer to record the modifications of shape memory properties, which appear after the thermal-mechanical synchronized cycles.

The conditions for dilatometric analysis are the following: (1) the sample is heating from ambiance temperature $\left(25-30^{\circ} \mathrm{C}\right)$ up to $150^{\circ} \mathrm{C}$; (2) the heating rate for SMA is imposed to $5^{\circ} \mathrm{C} /$ min; (3) the sample cooling is made in same time with the furnace of dilatometer (the cooling rate is $10^{\circ} \mathrm{C} / \mathrm{min}$ ); (4) after cooling the sample is subjected to other number of thermalmechanical fatigue cycles; (5) with the specific software, can obtain dilatogram with the information about the analyzed SMA (Figures 23-25).

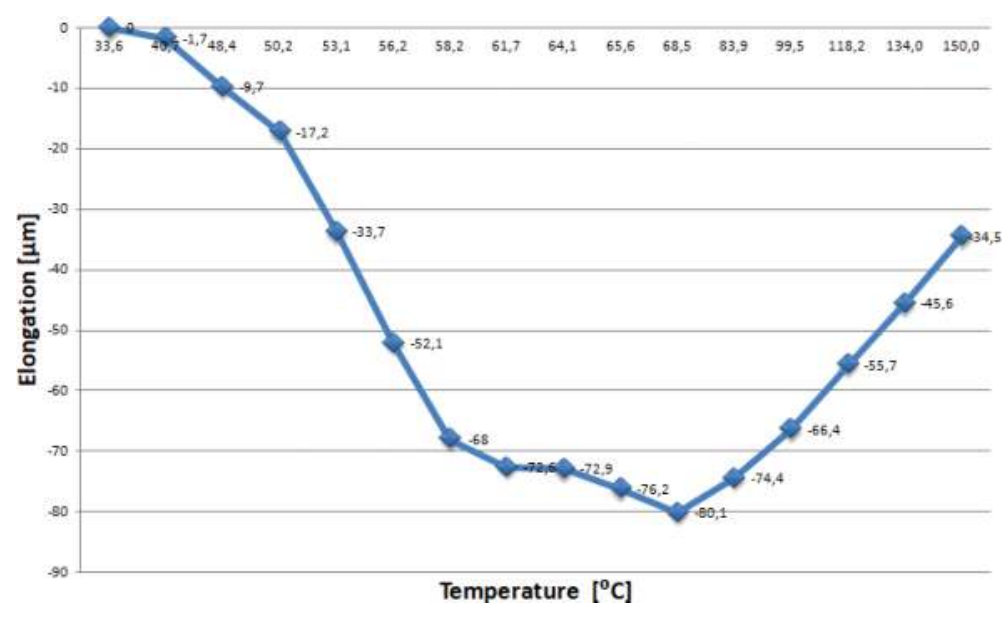

Figure 23. Dilatogram after 100 thermal-mechanical fatigue cycles.

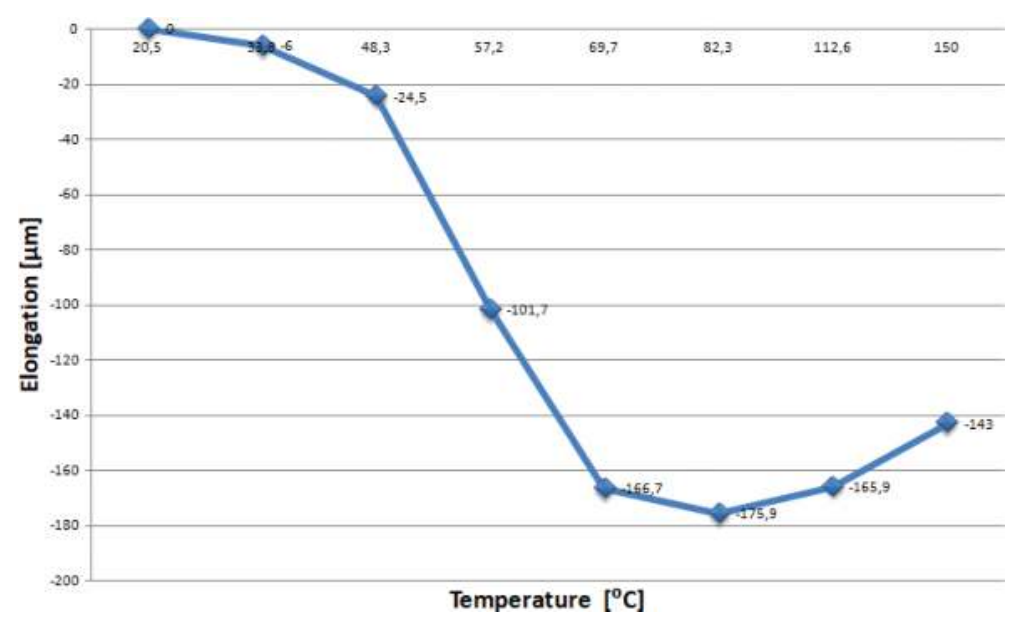

Figure 24. Dilatogram after 6985 thermal-mechanical fatigue cycles. 


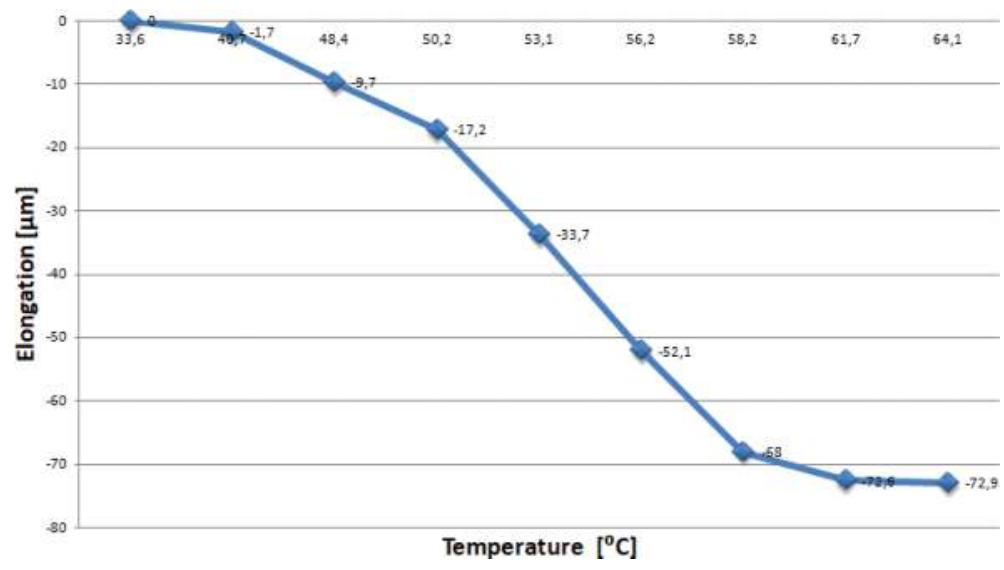

Figure 25. Dilatogram after 12,685 thermal-mechanical fatigue cycles.

\begin{tabular}{|c|c|c|c|}
\hline \multirow[t]{2}{*}{ Number of load cycles $\mathbf{N}$} & \multirow[t]{2}{*}{ Maximum contraction values $\Delta \mathrm{l}(\mu \mathrm{m})$} & \multicolumn{2}{|c|}{ Transformation temperatures $\left({ }^{\circ} \mathrm{C}\right)$} \\
\hline & & Ms & Af \\
\hline 0 & 30.70 & 65.8 & 102.2 \\
\hline 100 & 80.10 & 40.7 & 99.5 \\
\hline 200 & 79.70 & 40.2 & 67.0 \\
\hline 300 & 57.70 & 42.3 & 56.8 \\
\hline 400 & 83.80 & 37.7 & 68.0 \\
\hline 500 & 71.30 & 42.0 & 69.5 \\
\hline 600 & 74.90 & 44.0 & 72.2 \\
\hline 700 & 80.00 & 47.3 & 72.3 \\
\hline 800 & 88.70 & 49.2 & 75.3 \\
\hline 900 & 103.50 & 45.0 & 71.7 \\
\hline 1000 & 96.10 & 47.9 & 77.0 \\
\hline 1100 & 103.60 & 40.1 & 70.2 \\
\hline 1200 & 80.20 & 48.5 & 73.3 \\
\hline 1328 & 83.20 & 45.3 & 72.3 \\
\hline 1667 & 118.70 & 39.9 & 80.1 \\
\hline 2131 & 159.40 & 37.3 & 75.9 \\
\hline 2680 & 127.30 & 43.8 & 72.2 \\
\hline 3293 & 165.00 & 36.8 & 71.3 \\
\hline 4103 & 149.10 & 42.4 & 77.5 \\
\hline 4582 & 155.10 & 42.3 & 83.8 \\
\hline 5758 & 186.30 & 42.9 & 79.8 \\
\hline 6958 & 175.90 & 33.9 & 82.3 \\
\hline
\end{tabular}




\begin{tabular}{llll}
\hline Number of load cycles $\mathbf{N}$ & Maximum contraction values $\Delta \mathbf{l}(\mu \mathrm{m})$ & \multicolumn{2}{l}{ Transformation temperatures $\left({ }^{\circ} \mathbf{C}\right)$} \\
\cline { 3 - 4 } & & Ms & Af \\
\hline 8068 & 150.80 & 37.2 & 76.7 \\
9355 & 134.20 & 29.4 & 73.3 \\
10,948 & 123.00 & 28.5 & 81.6 \\
11,321 & 123.70 & 26.0 & 73.5 \\
12,209 & 69.60 & 28.0 & 64.0 \\
12,865 & 97.40 & 26.6 & 65.3 \\
\hline
\end{tabular}

Table 8. Measured parameters in fatigue study.

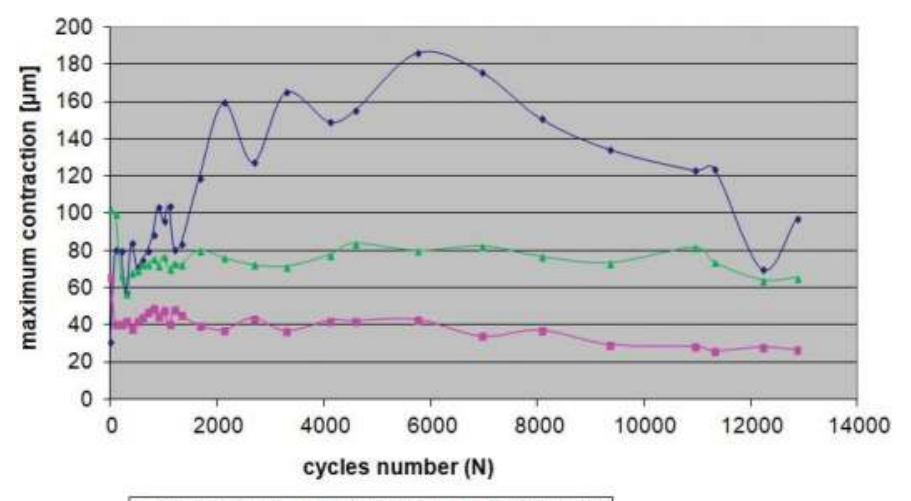

Figure 26. Variation of maximum contraction according the number of load cycles.

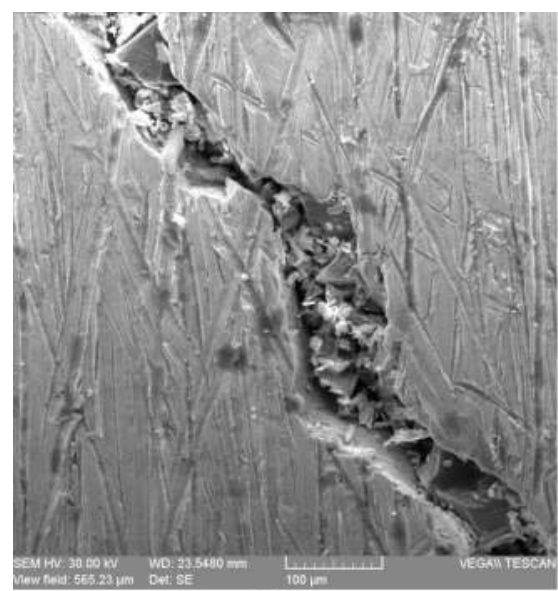

(a)

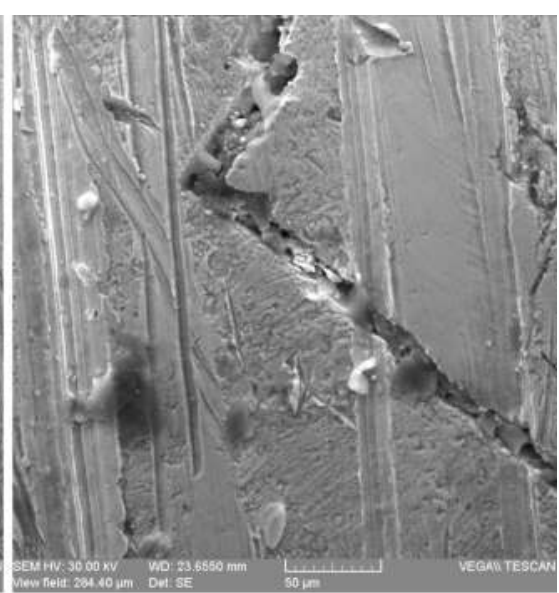

(b)

Figure 27. Micro-cracks on sample surface, after 12,865 fatigue cycles: (a) $500 \times$ and (b) $1000 \times$. 
Centralizing the maximum contraction values, after various number of thermal-mechanical fatigue cycles, can draw the fatigue curve for $\mathbf{C u}_{75} \mathbf{Z n}_{18} \mathbf{A l}_{6}$ alloy (Table 8) (Figure 26).

After 12,685 thermal-mechanical fatigue cycles, on sample surface appeared some microcracks (Figure 27). The experimental tests were stopped. If it continued, these micro-cracks will evolve in the analyzed sample and finally will have his breaking. Figure 27 presents the aspect of micro-cracks, at different magnitudes.

\section{Conclusions}

- The $\mathbf{C u}_{75} \mathbf{Z n}_{18} \mathbf{A l}_{6}$ studied alloy was obtained through classic elaboration, on an induction furnace, using alloying elements with high purity. Any influence in elaboration process, with modifications in percents calculus of alloying elements, can lead to obtaining an alloy with SME. A variation with $1 \%$ for aluminum or zinc can modify the critical points.

- For thermal-mechanical fatigue tests of SMA, a prototype installation has been designed and realized. The fatigue tests were completed with dilatometric analysis to highlight the deteriorations of SME.

- The $\mathbf{C u}_{75} \mathbf{Z n}_{18} \mathbf{A l}_{6}$ is a ternary alloy and the structure contains inter-metallic compounds, like $\mathrm{Cu}_{5} \mathrm{Zn}_{8}$ and $\mathrm{Al}_{4} \mathrm{Cu}_{9}$, for the sample in cast state (Figure 10).

- After a hot plastic deformation (forging at $850-800^{\circ} \mathrm{C}$ ), the structure is finishing and contains the following compounds: $\mathrm{AlCu}_{3}(20.5 \%), \mathrm{Cu}_{5} \mathrm{Zn}_{8}(33.3 \%), \alpha-\mathrm{Cu}_{0.61} \mathrm{Zn}_{0.39}$ (25.6\%) and CuZn (20.6\%) (Figure 14).

- After quenching to put into solution, in the structure, $\mathrm{AlCu}_{3}(42.8 \%)$ and $\mathrm{Cu}_{5} \mathrm{Zn}_{8}(51.2 \%)$ are found (Figure 18).

- Regarding the medium thermal conductivity can remark the following: (1) in cast state: $41.06[\mathrm{~W} / \mathrm{m} \cdot \mathrm{K}]$; (2) in forged state: $36.79[\mathrm{~W} / \mathrm{m} \cdot \mathrm{K}]$; (3) in quenched state: $6.35[\mathrm{~W} / \mathrm{m} \cdot \mathrm{K}]$ (Tables 4-6). The decrease of thermal conductivity for quenched sample more than six times over cast sample or forged sample. This fact transform this SMA in a thermal barrier, following in the heating-cooling process, the stored energy can be used in DSSME goal.

- The structure or $\mathrm{Cu}_{75} \mathrm{Zn}_{18} \mathrm{Al}_{6}$ alloy was analyzed through optical and SEM microscopy. The microstructures present the modifications of grains orientation and geometrical dimensions of martensite variants. The phenomenon is owed to the appearance of induced martensite under load, together with martensite thermal formed. The cast structure has a high granulation, with defects like goals, pores and chemical segregations.

- After hot plastic deformation through forging, the grains dimension are not modify, unless their orientation on deformation direction.

Although the SMAs have a large application domain, the obtaining of parts made from SMAs at industrial level is limited due to processing difficulties. The good shape memory properties can guarantee the functioning time for various parts, used in industrial applications. 


\section{Author details}

Petrică Vizureanu*, Dragoș-Cristian Achiței, Mirabela-Georgiana Minciună and Manuela-Cristina Perju

*Address all correspondence to: peviz2002@yahoo.com

“Gheorghe Asachi” Technical University of Iași, Romania

\section{References}

[1] Achiței DC, Abdullah MMA, Sandu AV, Vizureanu P, Abdullah A. On the fatigue of shape memory alloys. Advanced Materials Engineering and Technology II. 2014;594-595:133. DOI: 10.4028/www.scientific.net/KEM.594-595.133

[2] Samoilă C, Cotfas P, Cotfas D, Ursuțiu D, Vizureanu P, Aliaje cu memoria formei; 2011; Brasov, Editura Universității Transilvania. ISBN 978-973-598-934-7

[3] Available from: https://www.linseis.com/

[4] Available from: http://standardservice.ro/spectrometre/

[5] Available from: http://www.panalytical.com/Xray-diffractometers.htm

[6] Available from: http://ctherm.com/products/tci_thermal_conductivity/

[7] Available from: https://www.zeiss.com/microscopy/us/products/light-microscopes/axioobserver-for-materials.html

[8] Available from: https://www.tescan.com/en-us/technology/sem/vega3 